\title{
HLA-mediated tumor escape mechanisms that may impair immunotherapy clinical outcomes via T-cell activation (Review)
}

\author{
JOSEFA A. RODRÍGUEZ
}

\author{
Cancer Biology Research Group, National Cancer Institute of Colombia, 111511 Bogotá, Colombia
}

Received August 27, 2016; Accepted March 31, 2017

DOI: $10.3892 / \mathrm{ol} .2017 .6784$

\begin{abstract}
Although the immune system provides protection from cancer by means of immunosurveillance, which serves a major function in eliminating cancer cells, it may also lead to cancer immunoediting, molding tumor immunogenicity. Cancer cells exploit several molecular mechanisms to thwart immune-mediated death by disabling cellular components of the immune system associated with tumor recognition and rejection. Human leukocyte antigen (HLA) molecules are mandatory for the immune recognition and subsequent killing of neoplastic cells by the immune system, as tumor antigens must be presented in an HLA-restricted manner to be recognized by $\mathrm{T}$-cell receptors. Impaired HLA-I expression prevents the activation of cytotoxic immune mechanisms, whereas impaired HLA-II expression affects the antigen-presenting capability of antigen presenting cells. Aberrant HLA-G expression by cancer cells favors immune
\end{abstract}

Correspondence to: Mrs. Josefa A. Rodríguez, Cancer Biology Research Group, National Cancer Institute of Colombia, 9-85 Avenue 1st, 111511, Bogotá, Colombia

E-mail: jrodriguezg@cancer.gov.co

Abbreviations: APC, antigen-presenting cells; $\quad \beta_{2} \mathrm{~m}, \quad \beta_{2}$ microglobulin; BMDC, bone marrow derived cells; $\mathrm{CD}$, cluster of differentiation; CTL, cytotoxic T-cell; CTLA-4, cytotoxic T-lymphocyte-associated protein 4; DC, dendritic cells; ESCC, esophageal squamous cell carcinoma; HLA, human leukocyte antigen; Ig, immunoglobulin; IL, interleukin; ILT, immunoglobulin-like transcript; KIR2DL4, killer cell immunoglobulin-like receptor, 2 immunoglobulin domains and long cytoplasmic tail 4; $\mathrm{LOH}$, loss of heterozygosity; mAb, monoclonal antibody; MDSC, myeloid derived suppressor cells; mHLA-G, membrane-bound human leukocyte antigen-G; NACT, neo-adjuvant chemotherapy; NK, natural killer; NKG, natural killer group; PD1, programmed cell death protein 1; PDL1, programmed cell death ligand 1; sHLA-G, soluble human leukocyte antigen-G; sHLA-Gev, extracellular vesicle-associated soluble human leukocyte antigen-G; sHLA-Gfree, free soluble human leukocyte antigen G; TAAs, tumor associated antigens; TAM, tumor-associated macrophages; TCR, T-cell receptor; Th, T helper cells; T-reg, regulatory T-cells

Key words: immunosurveillance, tumor microenvironment, human leukocyte antigens, tumor immune escape, immunotherapy, immune checkpoints escape by inhibiting the activities of virtually all immune cells. The development of cancer therapies based on T-cell activation must consider these HLA-associated immune evasion mechanisms, as alterations in their expression occur early and frequently in the majority of types of cancer, and have an adverse impact on the clinical response to immunotherapy. Herein, the concept of altered HLA expression as a mechanism exploited by tumors to escape immune control and induce an immunosuppressive environment is reviewed. A number of novel clinical immunotherapeutic approaches used for cancer treatment are also reviewed, and strategies for overcoming the limitations of these immunotherapeutic interventions are proposed.

\section{Contents}

1. Introduction

2. Cancer immune response: Host-protective while tumor promoting

3. Tumor microenvironment: Antitumor and tumor promoting

4. HLA-mediated escape mechanisms by cancer cells

5. Novel immunotherapeutic approaches against cancer

6. Conclusions

\section{Introduction}

Tumors are complex tissues composed not only of tumor cells, but also a repertoire of immune cells that give them special features to allow tumor growth and metastasis. These special features, proposed by Hanahan and Weinberg in 2011, provide the tumor with proliferative signal support, the avoidance of growth suppressors, cell death circumvention, cell immortality, angiogenesis, and invasive and metastatic activation. Two additional features are involved in cancer pathogenesis: The ability to reprogram the cellular metabolism to support neoplastic proliferation, and the ability to evade immune recognition and destruction by $\mathrm{T}$ and $\mathrm{B}$ lymphocytes, macrophages, and natural killer (NK) cells (1).

Cancer progression typically requires tumor cells to acquire the ability to avoid immune detection and destruction. Thus, understanding the interplay between the tumor, the immune system and the tumor microenvironment is of pivotal importance to providing the rationale for designing therapeutic approaches that trigger specific antitumor immune responses. 
Inducing an effective immune response against cancer by immunotherapeutic intervention is a challenge that depends on several factors of the tumor and the immune system functioning together to either eradicate tumors or promote immune evasion. One of the most important factors in the development of antitumor immunotherapies is the constitution of the tumor microenvironment (including immune cell types, cytokine profiles, acidity and oxygenation levels, molecular signatures) as this may positively or negatively impact the arrival and cytotoxic activity of effector cells, thus determining an improved or worse clinical outcome (2). Therefore, to improve immunotherapy outcomes, it is important to alter the tumor microenvironment so that it is permissive for cytotoxic NK and T-cell activity. Thus, depending on the specific disease phenotype of the patient, certain therapeutic approaches must be escalated, while others should be avoided, in order to obtain a desirable clinical response (3).

Altered HLA (human leukocyte antigen)-I expression on the tumor cell surface is an early and frequent event that promotes carcinogenesis, as HLA-I is critical for the immune recognition of tumor cells and signaling between tumor and immune cells $(4,5)$. Several studies reported total or partial loss of classical HLA-I molecule expression in different human tumors $(6,7)$, with at least $50 \%$ of multiple HLA allele loss caused by loss of heterozygosity ( $\mathrm{LOH}$ ) events (8). Another HLA-mediated strategy used by tumor cells to avoid recognition by various immune effectors is the aberrant expression of non-classical HLA-I molecules (HLA-E and HLA-G), which function as inhibitor ligands for immune-competent cells, allowing tumor immune escape (9).

As mentioned previously, the complexity of the alterations to HLA expression in carcinogenesis makes selecting a therapeutic target to potentiate antitumor immune responses very difficult. However, correcting these alterations may provide a first step towards improving the currently available cancer immunotherapies.

\section{Cancer immune response: Host-protective while tumor promoting}

It is possible to separate tumor associated antigens (TAAs) into two main classes: Self and tumor-restricted antigens. Self-antigens include differentiation (including Melan A in melanoma) and overexpressed antigens (including ErbB2 receptor tyrosine kinase 2 in colon, breast and lung cancer), whereas tumor-restricted antigens may be of viral origin (including human papilloma virus in cervical and throat cancer), from the germ line (including NY-ESO-1 in melanoma) or neoantigens (for example mutated antigens, including $\beta$-catenin in melanoma) (10). It is possible to induce immunization against tumor self-antigens, potentially generating an effective antitumor T-cell and antibody response (11).

During carcinogenesis, innate and adaptive immunity stimulation occurs. Innate immunity mediates surveillance and tumor lysis in a rapid and non-specific fashion, whereas adaptive immune response is more specific; directed by TAAs that induce T-cell responses and antibody production (12). The main immune effectors of antitumor innate immunity are NK cells, which serve important functions in cancer immune surveillance: These cells express a variety of activating and inhibitory receptors that recognize cellular stress ligands, as well as major histocompatibility complex class I and similar molecules. These interactions mediate their tolerance to healthy self-cells and their cytotoxicity against stressed cells (13-15).

NK cell cytotoxic activity is either direct or indirect. Direct killing occurs via antibody-dependent cell-mediated cytotoxicity, an adaptive immune cell-killing mechanism mediated by activated NK cells (16), whereas indirect killing occurs through the secretion of cytokines, which exert antitumor effects via the stimulation of immune system regulatory components (17).

Although the main adaptive immune effectors capable of eliminating transformed cells are cytotoxic $\mathrm{CD}^{+} \mathrm{T}$-cells (18), $\mathrm{CD}^{+} \mathrm{T}$-cells, through the secretion of a Th1 cytokine profile (19), and B-cells, through the production of antitumor antibodies, also serve important functions in generating a powerful antitumor immune response. However, tumor features, including the nature of tumor antigens (20), immune modulatory factors produced by tumor and host immune cells, and the existence of regulatory cells [including regulatory T-cells (T-regs), myeloid derived suppressor cells (MDSCs) and tumor-associated macrophages (TAMs)] favor tumor development and progression (21).

The shift from antitumor innate immunity to a long-lasting adaptive immune response is mediated by lymphoid cells and their products (22). Genetic and epigenetic alterations generate tumor antigens that are recognized by a T-cell's T-cell receptor (TCR) when presented in an HLA-restricted manner. This recognition leads to T-cell priming, activation, proliferation, differentiation and cytokine production, and thus is pivotal for immune response amplitude and quality. Once tumor antigen recognition occurs, CD28 amplifies TCR signaling to completely activate T-cells. These activated effector T-cells leave the lymph nodes in search of tumor cells bearing the cognate HLA-peptide, leading to tumor cell death by T-cell mediated cytotoxicity (23). Under normal physiological conditions, T-cell activation is regulated by a balance between co-stimulatory and inhibitory signals, which ultimately leads to an effective immune response. Immune-suppressing pathway proteins, collectively termed immune checkpoints, are crucial for the maintenance of self-tolerance and for protection from tissue damage caused by the immune response itself (24). Tumors may alter immune homeostasis, suppressing T-cell activation and effector function, driving T-cell tolerance by chronic antigenic stimulation, and simultaneously activating suppressor pathways to prevent T-cell mediated killing. The immune checkpoint molecules associated with these phenomena have been demonstrated to be excellent targets for cancer immune therapy (25).

The best understood co-stimulatory/regulatory pathways are those mediated by CD80, CD86, cytotoxic T-lymphocyte-associated protein (CTLA)-4 and programmed cell death protein (PD)-1. CD80 and CD86 are expressed on the surface of antigen-presenting cells (APCs), bind to CD28 receptors on the T-cell surface and induce interleukin (IL)-2 production to support specific T-cell expansion (26). Once TCR activation occurs, regulatory signals are generated to limit the expansion and activation of TCR-triggered T-cells. CTLA-4 and programmed cell death protein 1 (PD1) are immune 
checkpoints capable of limiting T-cell activation in secondary lymphoid organs and activating T, B and myeloid cells $(27,28)$. Upon receptor ligation, T-cells stop clonal expansion and cytokine production (29-31). These regulatory signals compete for ligands and key substrates with co-stimulatory receptors. For example, on activated T-cells, CTLA- 4 competes with CD28 molecules for the CD80 and CD86 ligands on APCs to regulate cell cycle proteins and cytokine expression. Another immune check point with pivotal relevance in cancer is HLA-G, a tolerogenic non-classical HLA-I molecule, which binds to CD8 (32), CD160 (33), the inhibitory receptors immunoglobulin (Ig)-like transcript (ILT)-2 and -4, and killer cell Ig-like receptor, 2 Ig domains and long cytoplasmic tail 4 (KIR2DL4) $(34,35)$. Besides ILT-4, all these inhibitory receptors are widely expressed on lymphoid immune cells, whereas myeloid immune cells express CD8, ILT-2 and ILT-4 (36). Thus, immune responses are regulated in order to guarantee an effective immune response while preventing excessive immune activation.

In cancer, tumor cell plasticity may generate tumors with low immunogenicity in response to selective immune pressure exerted by the host immune system, enabling tumor evasion of immune surveillance. This host-protective, tumor-promoting immunity action is known as cancer immune editing, a process that occurs in three sequential phases: i) Elimination; ii) equilibrium and iii) escape (37). Elimination corresponds to the initial phase of cancer immune surveillance, in which the immune system is able to detect and destroy transformed cells, preventing tumor progression. In this phase, immune effector cells, including cytotoxic T-lymphocytes (CTLs) and NK cells, are able to recognize and eliminate tumor cells. Dendritic cells (DC) and CD4 ${ }^{+} \mathrm{T}$-cells are also components of this elimination phase, as they recognize and kill transformed cells long before they become clinically apparent, working as extrinsic tumor suppressors (38). Killing at this phase depends on i) stress ligand expression, including NK group (NKG) 2D; ii) TAA recognition in an HLA-restricted manner and iii) and co-stimulatory signals which completely activate T-cells (39).

Tumor cell variants that survive the elimination phase enter into an equilibrium stage in which the immune system controls tumor outgrowth, but the tumor remains clinically undetectable. Tumor cells with edited immunogenicity eventually continue growing; tumor dormancy is broken, and the edited tumors, which exhibit reduced immunogenicity, grow without immune control and progressively establish an immunosuppressive microenvironment, becoming clinically apparent $(40,41)$. Immuno-editing provides tumor cells with a plethora of molecular tools with which they may control the immune response. The tumor may recruit all immune cells and once inside, they participate in dynamic crosstalk with cancer cells to govern tumor development (Fig. 1). Early eradication or spontaneous tumor regression, as well as tumor promotion and development, depend on the nature of immune cells infiltrating the tumor and on tumor-induced immune factor production (37).

\section{Tumor microenvironment: Antitumor and tumor promoting}

The adaptive antitumor immune response is not always capable of tumor eradication, potentially due to immune evasion mechanisms including the induction of immunological ignorance and immunological tolerance, or interactions between tumor cells and the host immune response. These phenomena may inhibit T-cell activation and induce tumor resistance against immune attack (37), and are activated by a number of mechanisms that will be described.

At the initial tumor growth stage, tissue damage induces acute Th1 inflammatory responses that favor APC maturation and innate immune cell polarization, promoting the elimination of developing tumors. APC maturation initiates adaptive immune responses mediated by $\mathrm{CD}^{+}$and $\mathrm{CD} 8^{+} \mathrm{T}$-cells. Simultaneously, the acute activation of B-cells results in the induction of soluble mediators, including antigen-specific Igs capable of complement activation, to coordinate phagocytic or cytotoxic destruction of damaged cells by innate immune cells (42). During inflammation, chemokines control immune cell movement, immune response polarization and T-cell and dendritic cell interactions, while cytokines mediate intercellular communication in the immune system and function as immune regulators $(43,44)$. Chemokine and cytokine expression profiles modulate the functional status of the immune system to negatively impact tumor development and progression.

In cancer development, tumor cells and tumor infiltrating immune cells produce antitumor and pro-tumor immune factors, which modulate the tumor immune response. A pro-tumor effect may dominate through various means: Inflamed tumors express high levels of pro-inflammatory innate and adaptive immune signals, as well as several immune-inhibitory factors, including programmed cell death ligand (PDL) 1 and indoleamine-2, 3-dioxygenase. They also recruit forkhead box $\mathrm{p} 3$ and T-regs to promote immune escape. Alternatively, non-inflamed tumors express a reduced level of chemokines, resulting in the poor attraction of $\mathrm{CD} 8^{+}$ effector T-cells into the tumor mass and poor effector cell trafficking (45). In addition, high levels of vascular markers and high macrophage and fibroblast infiltration also favor tumor growth (Fig. 2) (46,47). TAMs, tolerogenic DCs, regulatory T-cells and MDSCs, which are the main regulatory immune cells recruited by the tumor to create an environment with anti-inflammatory properties, favor tumor growth and survival (45). In addition, the chronic activation of B-cells is deleterious in certain types of cancer, potentially through the production of IL-10 (48). Thus, the nature of immune cells infiltrating the tumor serves a fundamental function in the failure of antitumor immune responses. In breast cancer, immune cell infiltration was previously demonstrated to correlate with an improved prognosis, a reduced tumor diameter and longer recurrence-free survival time (49). In other types of cancer, high $\mathrm{CD} 4^{+} \mathrm{T}$-cell infiltration was identified to correlate with tumor progression, potentially because the main tumor infiltrating cells are $\mathrm{CD} 4^{+}$T-reg cells (50).

Alternatively, IL-10 in the tumor microenvironment may generate a neoplastic cell phenotype resistant to CTL-mediated lysis by decreasing transporter associated with antigen processing (TAP) $1 / 2$ expression and function, resulting in low peptide translocation into the endoplasmic reticulum, thus affecting HLA-I-mediated antigen presentation $(51,52)$. HLA-I downregulation and non-classical HLA-I molecule neo-expression promote immunosuppression and, therefore, 


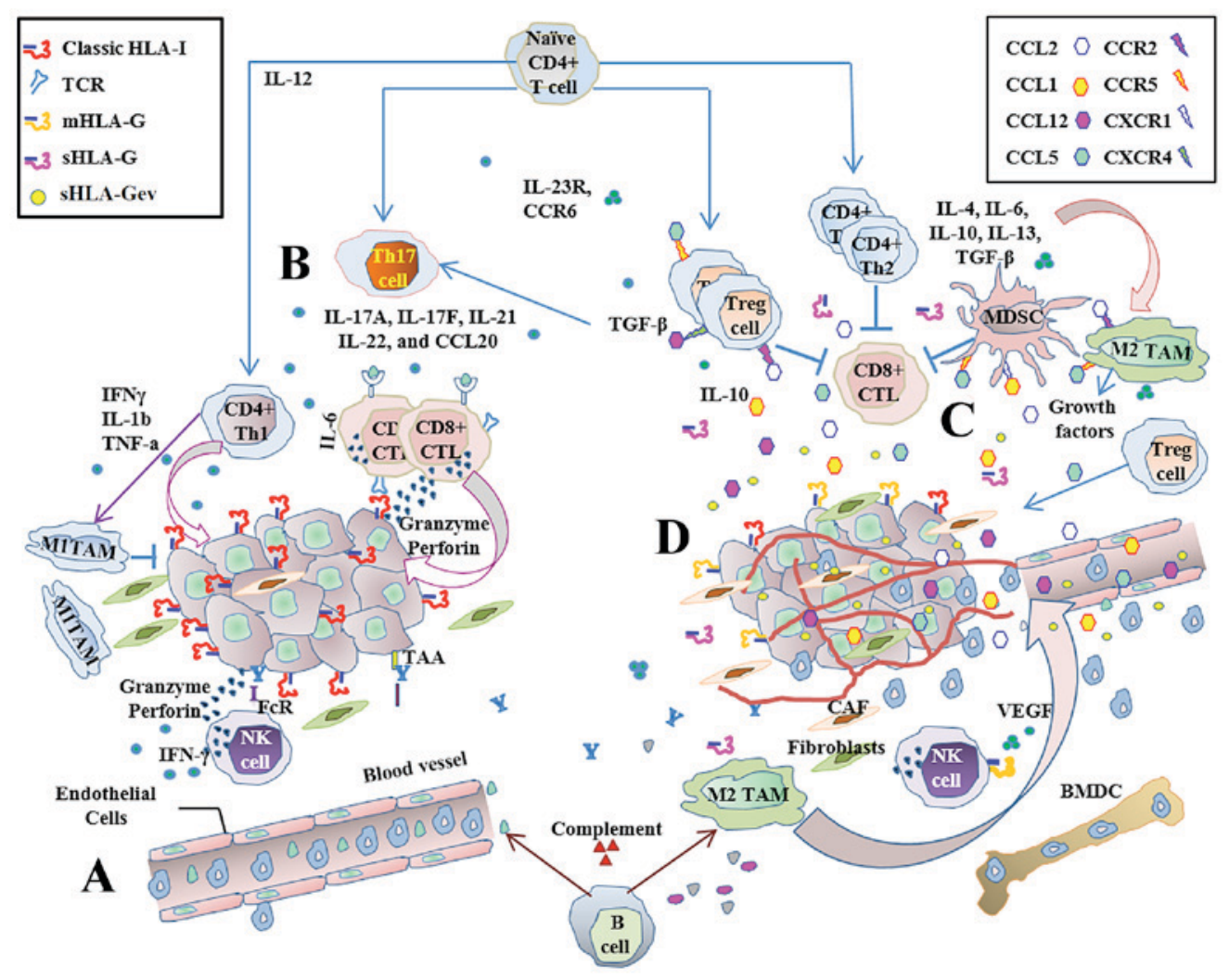

Figure 1. Immune response to cancer: Host-protective while tumor-promoting. The innate and adaptive immune responses are stimulated during carcinogenesis and are capable of surveillance and tumor lysis. (A) The main antitumor immune effectors are NK and CD8 ${ }^{+} \mathrm{T}$-cells, which are capable of responding directly against cancer with cytotoxicity, or by secreting cytokines. Inflammatory cells infiltrate the tumor and exert antitumor immune responses. (B) Cytotoxic CD ${ }^{+}$ T-cells are the main adaptive immune effectors. $\mathrm{CD} 4{ }^{+} \mathrm{T}$-cells help to improve antitumor immune responses through the secretion of Th1 cytokines. Antitumor immune responses mediated by CTLs are effective and prevent tumor development in HLA-I positive tumor cells, but these immune responses are ultimately insufficient to prevent disease progression. (C) When inflammatory responses become chronic, regulatory cell populations generate a tolerant pro-tumor immune response via cytokine secretion and the production of growth factors. Tumor-promoting activity favors angiogenesis, invasion and metastasis, and is capable of suppressing adaptive immunity. (D) Aberrant expression of classical and non-classical HLA-I contributes to the establishment of an immunosuppressive microenvironment, promoting tumor growth by controlling immune stimulation and suppression signals. NK, natural killer; $\mathrm{CD}$, cluster of differentiation; CTL, cytotoxic T-cell; HLA, human leukocyte antigen; BMDC, bone marrow-derived cells; CAF, cancer-associated fibroblast; CCL, C-C motif chemokine ligand; CCR, C-C motif chemokine receptor; CXCR, C-X-C motif chemokine receptor; FcR, fragment crystallizable receptor; IFN, interferon; IL, interleukin; MDSC, myeloid derived suppressor cells; mHLA-G membrane-bound human leukocyte antigen-G; sHLA-G, soluble human leukocyte antigen-G; sHLA-Gev extracellular vesicle-associated soluble human leukocyte antigen-G; TAAs, tumor associated antigens; TAM, tumor-associated macrophages; TCR, T-cell receptor; TGF- $\beta$, transforming growth factor $\beta$; Th, T helper cells; T-reg, regulatory T-cells.

tumor immunoescape. A number of studies have demonstrated that HLA-G, HLA-E and IL-10 expression levels in cancer are associated with tumor progression, metastasis and a poor prognosis (53-55), and that the IL-10-positive T-reg cell frequency may be associated with malignant transformation by contributing to immunosuppression in the tumor microenvironment (56). Due to the plethora of possible immunosuppressive features present in a particular tumor entity, it is necessary to personalize the selection of the therapeutic targets for cancer treatment to induce an effective antitumor immune response, thus avoiding the development of tumor chemo-resistance and a subsequent poor outcome.

\section{HLA-mediated cancer cell escape mechanisms}

The malignant transformation of cells is often associated with alterations to gene expression and the antigenic profile. Alterations in HLA expression (including classical and non-classical HLA-I and HLA-II) are frequent and early events during carcinogenesis $(4,57)$. As tumor cells are immunogenic, they must acquire a plethora of molecular mechanisms to avoid destruction by CTLs and NK cells. By downregulating classical HLA-I, they prevent tumor recognition and rejection by CTLs, and by overexpressing non-classical HLA-I molecules they disable all types of immune cell involved in tumor recognition and rejection (including T and B lymphocytes, APCs and NK cells) (58). Conventional changes of HLA expression in malignant cells include total or allele-specific loss of classical HLA-I expression and the induction of non-classical HLA-I and HLA-II expression, potentially due to an immune selection process that enables the initiation of malignant lesions with an HLA-altered phenotype, which will be necessary to consider when designing novel immunotherapies for cancer treatment (59).

HLA expression is crucial for the generation of adaptive immunity, as tumor antigens are presented in an HLA-restricted manner to T-cells, activating them and controlling immune crosstalk (60). Altered HLA expression on the tumor cell surface has been described in a variety of human tumors, with percentages ranging from $60-90 \%$ expression in different human tumor types $(4,61)$. These alterations result in different HLA-altered phenotypes, including 


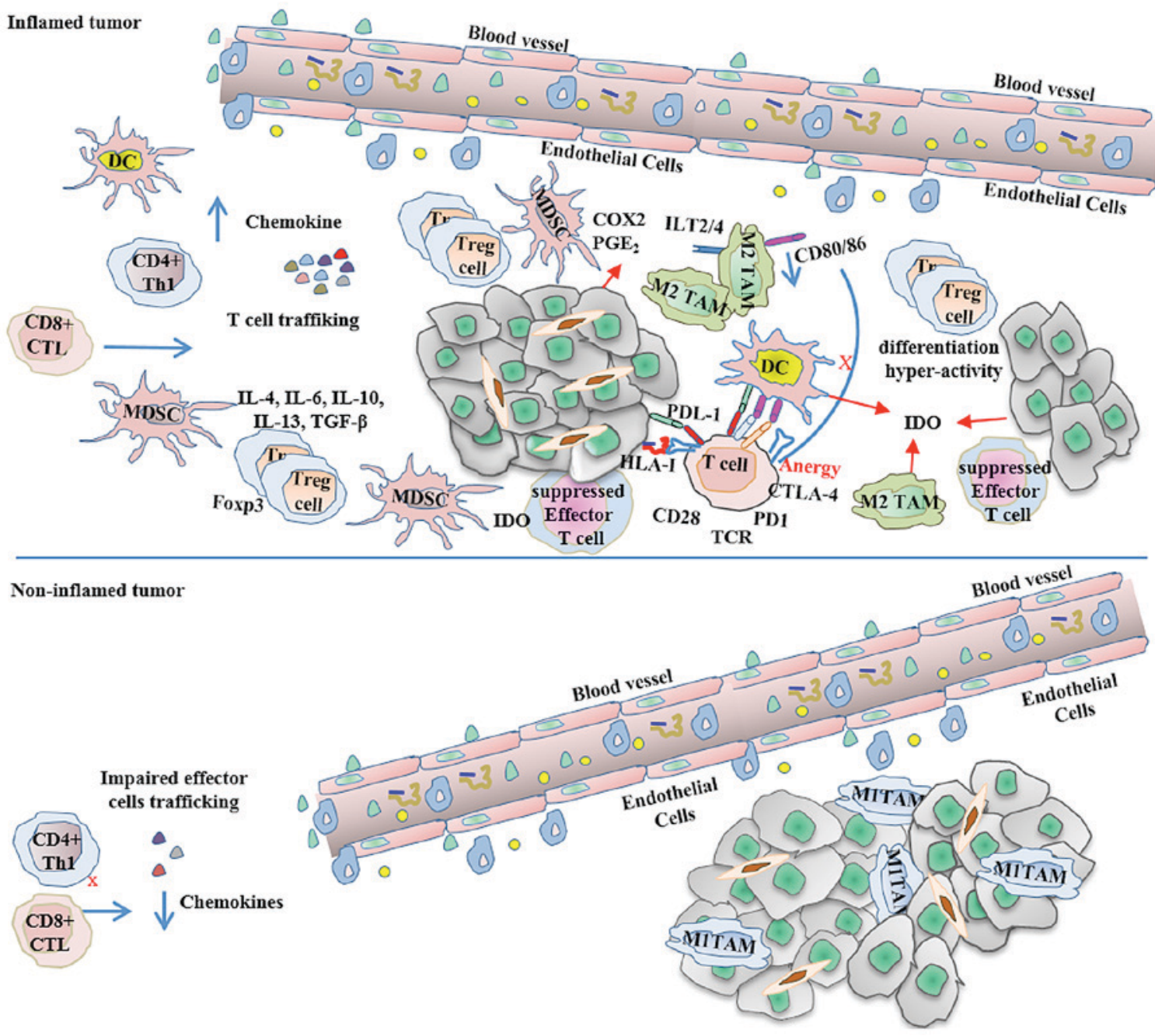

Figure 2. Inflamed and non-inflamed tumors escape immune-mediated destruction. As described by Gajewski et al (44), inflamed tumors express high levels of pro-inflammatory innate and adaptive signals, as well as immunoregulatory factors that contribute to the creation of an immunosuppressive environment, in which a dominant effect of negative regulation mediates the tumor escape. In contrast, non-inflamed tumors with poor chemokine production have few effector cells, abundant macrophages and cancer-associated fibroblasts, and express high levels of vascular markers, also allowing tumor escape. CD, cluster of differentiation; COX2, cytochrome c oxidase 2; CTL, cytotoxic T-cell; CTLA-4, cytotoxic T-lymphocyte-associated protein 4; DC, dendritic cells; Foxp3, forkhead box p3; HLA, human leukocyte antigen; IDO, indoleamine-2, 3-dioxygenase; IL, interleukin; ILT, immunoglobulin-like transcript; MDSC, myeloid derived suppressor cells; PD1, programmed cell death protein 1; PDL1, programmed cell death ligand 1; PGE2, prostaglandin E2; TAM, tumor-associated macrophages; TCR, T-cell receptor; TGF- $\beta$, transforming growth factor $\beta$; Th, T helper cells; T-reg, regulatory T-cells.

the neo-expression of non-classical HLA-I molecules like HLA-G, which primarily function as inhibitor ligands for immune-competent cells $(6,7)$, and HLA-E, which together with HLA-G and IL-10, is associated with the evasion and progression capacities in tumor entities including lip squamous cell carcinoma (62). HLA-G and HLA-E exhibit limited polymorphism, low cell surface expression and restricted tissue distribution (63). They exert several immune regulatory functions: HLA-G has immuno-tolerogenic properties and inhibits CTL and NK cell lytic functions (64), whereas HLA-E may act as an immuno-tolerogenic or immuno-activating molecule depending on the NK cell receptor it is attached to. HLA-G inhibits immune cells from binding to ILT2, ILT4 and KIR2DL4 receptors $(65,66)$, whereas HLA-E is the major ligand required for the inhibitory NK cell receptors CD94/NKG2A and CD94/NKG2B expressed in NKs and CTLs to produce immune tolerance, but also for the CD94/NKG2C activating receptor expressed on NK cells and cytotoxic T-cells to support their cytotoxic activity $(67,68)$. Thus, due to the pivotal immune function of HLA molecules, alterations in their expression may be the most common evasion mechanism used by tumor cells to avoid immune responses (39).

It is possible to classify HLA-altered tumor cell phenotypes into two main groups: Reversible regulatory or irreversible structural defects. Reversible HLA class I regulatory defects may occur at any step of synthesis, assembly, transport and/or molecular surface expression, and are caused by genetic, epigenetic, transcriptional or post-transcriptional events, resulting in regulatory abnormalities that it is possible to recover with cytokine treatment. In contrast, structural defects caused by mutation events that disrupt HLA-I heavy chain and $\beta_{2}$ microglobulin $\left(\beta_{2} \mathrm{~m}\right)$ genes are irreversible (69).

In cancer, HLA class I loss occurs frequently and is predominantly caused by genetic aberrations in chromosomes $6 \mathrm{p} 21.3$ and $15 \mathrm{q} 21$ (70). It has been reported that at least $50 \%$ of 


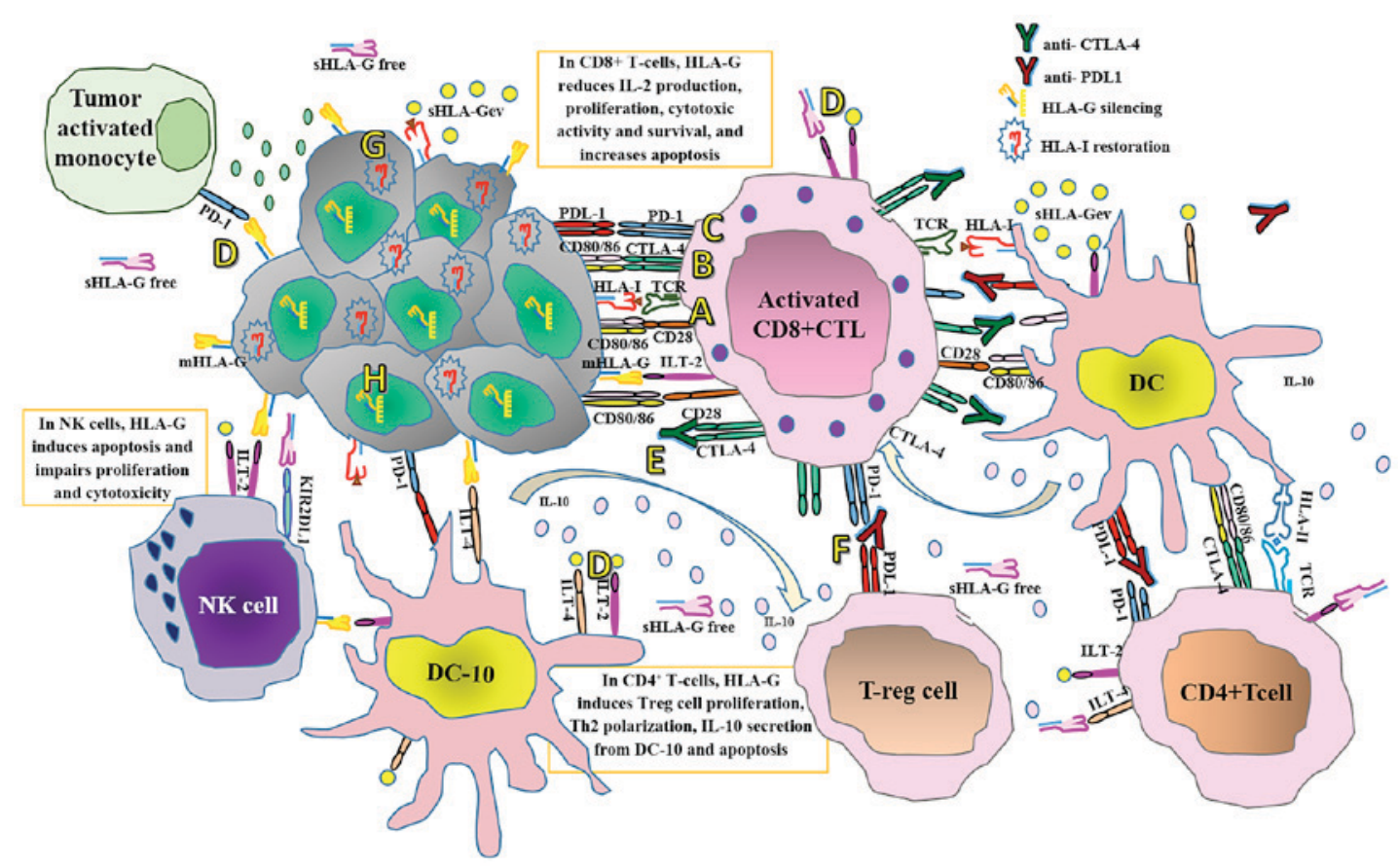

Figure 3. Current immune checkpoint blockade therapies and proposed adjuvant therapies for personalized cancer treatment. (A) T-cells are activated when TCRs bind antigens in a major histocompatibility complex-restricted manner on antigen presenting cells, in concert with CD28-CD80/CD86 mediated co-stimulation. (B) At the tumor site following T-cell activation, CTLA-4 is translocated on the T-cell surface and competes with CD28 for binding the CD80/CD86 ligands. This interaction delivers an inhibitory signal, which abrogates T-cell activation and proliferation. (C) Tumor cells express PDL1 and when this interacts with PD1 expressed by T-cells and other immune cells, it interferes with several T-cell signaling pathways that promote the induction of T-cell anergy, impairing the lytic capacity of T-cells on tumor cells at the HLA-I antigen-presenting stage. However, PD1 and CTLA-4 expression depend on T-cell activation that, in turn, depends on antigen recognition in an HLA-I-restricted manner. (D) On the other hand, interactions of membrane-bound and soluble HLA-G isoforms with their specific inhibitory receptors expressed by immune cells, including ILT-2, ILT-4 and KIR2DL4, impairs virtually all antitumor immune responses. In contrast to PD1 and CTLA-4, HLA-G expression does not require T-cell activation. (E) Thus, although therapy with anti-CTLA-4 monoclonal antibodies impairs the immunosuppressive CTLA-4 signal, promoting interactions between CD80/CD86 and CD28 and keeping T-cells activated, and (F) anti-PDL1 therapy may restore the activity of antitumor T-cells that have become quiescent, $(\mathrm{G})$ tumor cells bearing defective HLA-I expression may be refractory to these therapeutic approaches. Targeting the aberrant HLA-I expression at the tumor cell surface may improve the clinical efficacy of these approaches, and $(\mathrm{H})$ silencing HLA-G expression or blocking the inhibitory HLA-G receptors on immune cells may prevent inhibitory signaling and restore the effector antitumor capacity of immune cells. TCR, T-cell receptor; CD, cluster of differentiation; CTLA-4, cytotoxic T-lymphocyte-associated protein 4; PDL1, programmed cell death ligand 1; PD1, programmed cell death protein 1; HLA, human leukocyte antigen; ILT, immunoglobulin-like transcript; KIRD2L4, killer cell immunoglobulin-like receptor, 2 immunoglobulin domains and long cytoplasmic tail 4; DC-10, interleukin-10-secreting dendritic cells; DC, dendritic cells; IL, interleukin; mHLA-G, membrane-bound human leukocyte antigen-G; NK, natural killer; sHLA-Gev, extracellular vesicle-associated soluble human leukocyte antigen-G; sHLA-Gfree, free soluble human leukocyte antigen G; Th, T helper cells; T-reg, regulatory T-cells.

multiple HLA allele loss is caused by $\mathrm{LOH}$, which is a frequent mechanism for HLA haplotype loss in various types of human tumor (71). Irreversible total HLA-I loss frequently occurs due to the coincidence of two molecular events: Mutation of one $\beta_{2} \mathrm{~m}$ gene, and the loss of the second copy by LOH. This alteration has been described in various types of malignancy (72).

In cervical cancer, HLA-I downregulation occurs early in tumor development and is associated with HLA-G upregulation. The majority of HLA-G $\mathrm{G}^{+}$tumors also expresses IL-10, thus suggesting the involvement of IL-10 in the generation of an immunosuppressive environment, by downregulating classical HLA-I and upregulating HLA-G expression (73). The HLA-G primary transcript generates seven different protein isoforms by alternative splicing, including four membrane-bound isoforms, HLA-G1, G2, G3 and G4, and three soluble (s)HLA-G5, G6 and G7 isoforms (64). The soluble forms are secreted as free soluble HLA-G molecules (sHLA-Gfree) or in extracellular vesicles (sHLA-Gev), enabling tumors to inhibit virtually all immune cells (Fig. 3) (74,75).

HLA-G expression by the tumor prevents immune responses by a variety of strategies, including the prevention of cell lysis by CTLs and NK cells, the induction of tolerant myeloid DCs, and the induction of anergic or immunosuppressive CD4 ${ }^{+}$ and $\mathrm{CD} 8^{+}$T-cells (76). It has also been demonstrated that NK cells may acquire an immune-suppressive phenotype through HLA- $\mathrm{G}^{+}$tumor cell trogocytosis (77) and that sHLA-G exerts immunosuppressive functions by inducing apoptosis mediated by Fas cell surface death receptor/Fas ligand in circulating antigen specific T-cells (32). Furthermore, different sHLA-G subcomponents exhibit different prognostic impacts on the clinical outcome of patients with breast cancer treated with neo-adjuvant chemotherapy (NACT): High levels of sHLA-Gev prior to NACT were associated with disease progression and stem cell-like circulating tumor cells, whereas high sHLAGfree levels were associated with improved clinical outcome. However, total sHLA-G levels, without considering sHLA-Gfree and sHLA-Gev subcomponents, were not associated with clinical parameters $(65,78)$. HLA-G1 and HLA-G5 are the full-length membrane-bound and soluble isoforms, respectively, and require peptide association for their correct expression, whereas the other membrane-bound and soluble isoforms have low stability and have different in vivo functional activities $(9,79)$. 
HLA-II alterations also function in immune escape by impairing the antigen-presenting capability of peripheral blood monocytes in patients with acute leukemia (80). An association between HLA-II variants and breast cancer susceptibility has been suggested in Chinese breast cancer patients. In this population, HLA-II variants may be associated with prognosis: The expression of HLA-DQB1 may indicate a poor prognosis, whereas HLA-DRB5 may be associated with a good prognosis (81). In addition, aberrant expression of HLA-DRB1 and HLA-DQB1, which may occur due to aberrant gene methylation, serves key functions in the pathogenesis of esophageal squamous cell carcinoma (ESCC), by influencing immune response to specific tumor epitopes and by promoting ESCC occurrence and progression (82). Furthermore, in the population of Guangdong, China, the occurrence of certain HLA-II alleles, including DPB1*1301, DPB1*0202, DQB1*030302, and DQB1*050301, occurred with higher frequency in patients with cervical cancer than in controls, suggesting that they may confer susceptibility to cervical cancer. On the other hand, the occurrence of the DRB1*13-DQB1*06 haplotype was significantly lower in patients with cervical cancer compared with controls, suggesting that this haplotype may confer a decreased risk of cervical cancer within this population (83).

\section{Novel immunotherapeutic approaches against cancer}

Current therapies against cancer include chemotherapy (84), radiation therapy (85), immunotherapies (86), biological therapies and targeted therapies. Therapeutic schemes currently in clinical trials include cryosurgery, hyperthermia and cancer vaccines designed to prevent (prophylactic) or treat (therapeutic) cancer (84). A large volume of research is being produced concerning strategies to induce antitumor immunity, including via innate and adaptive effector mechanisms. The blockade of immune checkpoints may trigger the antitumor immune response, while co-stimulatory receptor agonists and inhibitory signals antagonists may induce antigen-specific T-cell response amplification, potentially transforming human cancer therapeutics (24). Currently, a range of therapeutic agents that exploit this mechanism are in clinical trials (Table I).

Although novel immunotherapeutic approaches with a number of different molecular targets and modes of action are currently in development, obstacles including difficulties in immunological monitoring, poor clinical trial design and the absence of cancer vaccine regulation make it difficult to achieve an adequate evaluation of effective immune responses following antitumor therapy. It is possible to overcome these obstacles by improving patient selection, using combined therapies to impact several immune signaling pathways simultaneously, identifying novel biomarkers to evaluate clinical responses and coordinating immunological monitoring for clinical trials. These improvements must be achieved prior to successful clinical translation (87). Combined therapies use checkpoint inhibitors as immunological adjuvants to boost cancer immunotherapy and vaccines. The inhibition of signaling pathways, including vascular endothelial growth factor to inhibit angiogenesis, epidermal growth factor receptor to inhibit proliferating signals or telomerase to interfere with replicative immortality enablement, are examples of targeting the hallmarks of cancer (1). Cytokines have potential therapeutic and preventive applications, but the associated systemic toxicity limits their use in treating cancer. To overcome this problem, novel recombinant antibody-cytokine fusion proteins have been designed to maximize cytokine therapy efficacy by exploiting the specific tumor-targeting ability of monoclonal antibodies (mAb) and the immune stimulatory ability of cytokines, to induce antitumor immune responses while preventing systemic toxicities of cytokine therapy alone (88).

The blockade of immune checkpoints using human immune-modulatory $\mathrm{mAbs}$ are in preclinical and clinical development. These mAbs target immune system components rather than the tumor itself, thus resulting in different responses to anti-CTLA-4 therapy (89), compared with conventional antitumor mAbs, chemotherapies and immunotherapies (including vaccines and cytokines) in terms of the pattern of response; such as the response time to the therapy, duration of response and adverse event profile (90). Another benefit of anti-immune checkpoint mAb therapy is that it is possible to use it to treat a variety of malignancies (91), including hepatocellular carcinoma, which constitutes a significant challenge for conventional cancer immunotherapy, as the unique immune response in the liver favors immune tolerance, impairing the therapeutic action of immunotherapy (92). The clinical use of these drugs induces immune-related adverse events, including rashes, colitis, thyroiditis and hepatitis, and clinical management for these symptoms typically consists of treatment discontinuation or symptomatic management with steroids or other immunosuppressive agents (93).

Activation of the immune system through CTLA-4,PD1 and programmed cell death ligand 1 (PDL1) immune checkpoint blocking is a promising cancer therapy strategy $(91,94)$. As the clinical success of targeting PD1/PDL1 or CTLA-4 depends on blocking the regulatory activities of the receptor-ligand interactions, it is important to consider that CTLA-4, PD1 and PDL1 expression depend on TCR activation, and that HLA-I expression on cancer cell surfaces is a prerequisite for a successful T-cell activation. Thus, lack of HLA-I expression by tumor cells has a major effect on tumor recognition and the further activation of T-cells, which remain unstimulated and incapable of recognizing cancer cells. In this scenario, anti-CTLA-4, -PD1 and -PDL1 therapies would not work (Fig. 3) (95). Thus, HLA status on the tumor cell surface must first be assured to determine the suitability of an immunotherapy treatment based on T-cell activation following TAA recognition.

Cancer immunotherapy strategies to activate T-cell-mediated antitumor responses include the use of antibodies to target inhibitory molecules that impair T-cell cytotoxicity (25), adoptive cell transfer with tumor infiltrating lymphocytes expanded in vitro (96), or genetically modified cytotoxic T-cells $(97,98)$. However, $\mathrm{CD}^{+} \mathrm{T}$-cells have been established to recognize and destroy HLA-I positive tumor cells. As human cancers are frequently characterized by alterations in HLA-I expression, attempts to treat cancer by increasing the $\mathrm{CD}^{+} \mathrm{T}$-cell response will be unsuccessful in patients harboring tumors with negative or deficient HLA-I expression. Thus, a requirement for achieving successful clinical responses following administration of T-cell activation based immunotherapy is, again, to verify whether these important molecules for T-cell cytotoxicity are correctly 


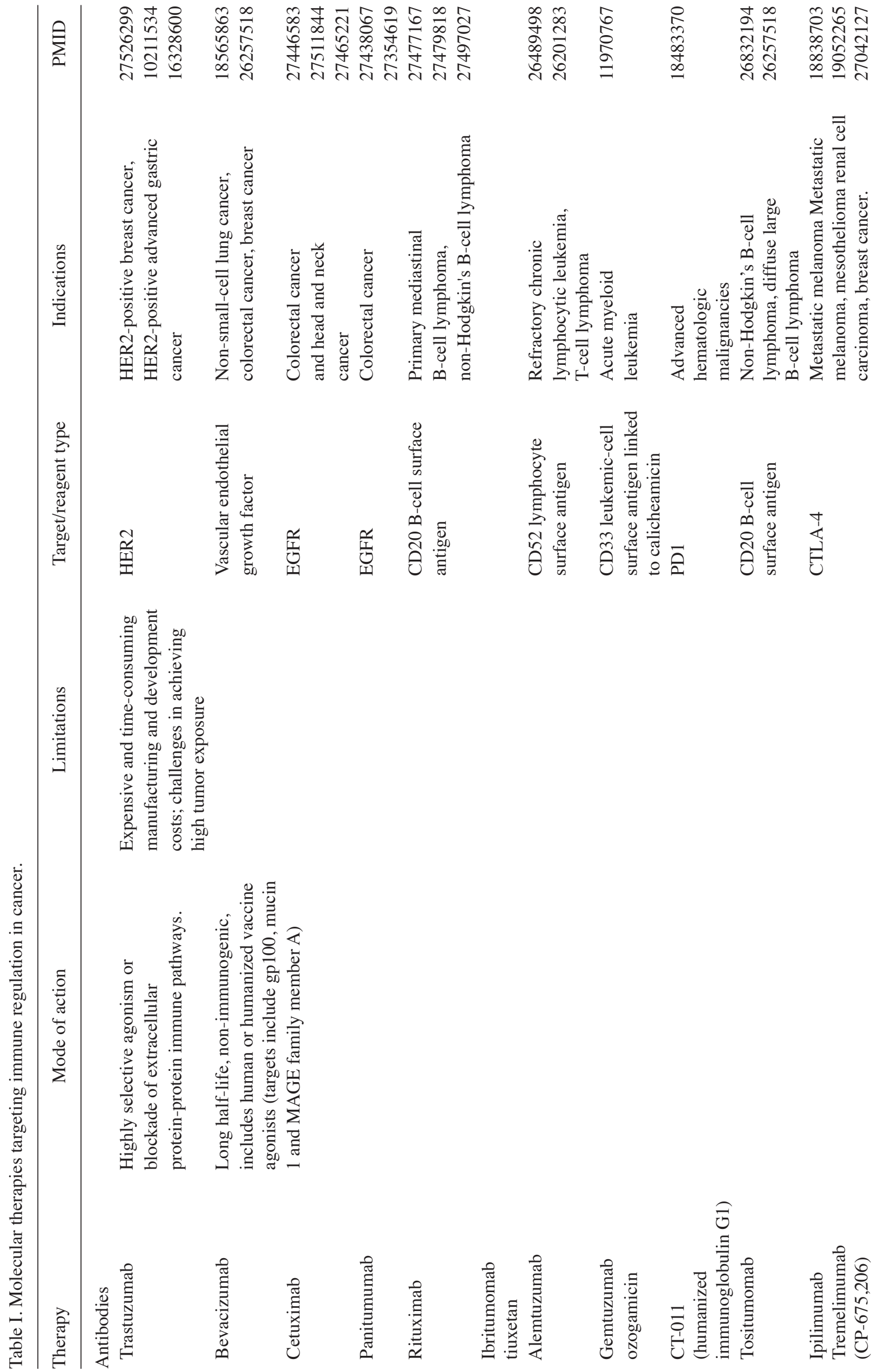







expressed by cancer cells. Such expression would be an appropriate predictive biomarker to determine which patients should enter into these treatment schemes (84). Other patients may first require a neo-adjuvant scheme to restore normal HLA expression on cancer cells prior to the utilization of T-cell activation or immune-checkpoint blockade-based immunotherapies.

A range of immunotherapeutic schemes have been designed to modify the tumor microenvironment to improve the response to therapy in patients with cancer; however, restoration of normal HLA-I expression in cancer cells is of pivotal importance to ensure the immunogenicity of these schemes. Current strategies to restore normal HLA-I expression work well only when the molecular mechanism mediating HLA-I downregulation is reversible, as when HLA-I downregulation is due to heavy chain structural defects its expression is difficult to correct. Adenovirus-mediated gene transfer may be a powerful strategy to correct HLA expression, as human $\beta_{2} \mathrm{~m}$ gene transfer to tumor cells negative for HLA-I following $\beta_{2} \mathrm{~m}$ structural alteration has been demonstrated to restore HLA-I expression on tumor cell surface (99). The restoration of HLA expression reestablishes tumor cell immunogenicity, thereby inducing T-cell activation in a peptide-specific, HLA-restricted manner, suggesting that gene transfer of the $\beta_{2} \mathrm{~m}$ gene may be a suitable neo-adjuvant therapy prior to T-cell activation-based immunotherapy in the patients harboring tumors negative for HLA-I due to $\beta_{2} \mathrm{~m}$ structural alteration (100). Table I further summarizes the main molecular therapies targeting immune regulation in cancer.

\section{Conclusions}

The benefit of conventional therapies is often limited by collateral damage to normal tissues. Radiotherapy induces massive cell death and chemotherapy toxicity is directed against all actively proliferating cells. During massive cell death, $\mathrm{CD} 8^{+}$ T-cells specific for tumor antigens undergo repeated TCR stimulation due to the persistence of TAAs. Chronically stimulated T-cells gradually lose their ability to secrete IL-2, tumor necrosis factor- $\alpha$ and interferon- $\gamma$, and are finally eliminated by apoptosis in a process known as T-cell exhaustion, which is characterized by the overexpression of inhibitory receptors (101). PD1, CTLA-4, lymphocyte-activation gene 3, T-cell Ig and mucin domain-3 and T-cell immunoreceptor with Ig and ITIM domains, among others (102), dampen the stimulation of an effective antitumor immune response by immunotherapeutic drugs. However, in patients with an exhausted immune system, blocking of these receptors leads to T-cell activation, suggesting that the restoration of a non-exhausted immune context may improve immune activation. Previous results have indicated that T-cell exhaustion is reversible, which may have profound implications for cancer treatment (103).

Novel immune-based therapies for cancer include adoptive cell therapy, tumor vaccines, cytokines or the inhibition of immune suppressive mechanisms including with immune checkpoint inhibitors, and the depletion of T-regs or MDSCs. The search for targets for the design and improvement of novel therapies should include the search for biomarkers to measure therapeutic activity and evaluate potential synergy among different immune-therapeutic modalities (104). However, as a large number of signaling pathways are typically associated with carcinogenesis, it is probable that a single therapeutic 
agent inhibiting one molecular target in a given tumor will not be sufficient to eradicate the entire tumor mass. Advances in knowledge of antitumor immune responses have been facilitated by the development of targeted therapies for cancer control, including anti-CTLA-4 antibodies, the therapeutic success of which suggests that immunotherapy may achieve long-lasting and durable antitumor immune responses in patients with cancer (105).

Blocking immune checkpoints may restore immune function in certain scenarios, depending on the HLA phenotype. In tumors with normal HLA-I expression, inhibitors of PD1 or anti-CTLA-4 mAbs function as PD1 and CTLA-4 expression depend on T-cell activation that, in turn, is dependent on HLA-restricted antigen recognition. Therefore, tumors bearing defective HLA-I expression may be refractory to these therapies due to their inability to present TAAs to CTLs. Reestablishment of normal HLA expression on the tumor cell surface by gene therapy may improve the clinical impact of anti-CTLA-4 and PD1 immunotherapies and restoring HLA-I expression may be an adjuvant therapy not only for TCR-stimulation-based immunotherapies, but also therapy based on checkpoint blocking. The combination of immunotherapy with conventional therapy, for example chemotherapy, has been demonstrated to produce a significant increase in the clinical response of patients with cancer, despite the toxicity caused by chemotherapy to immune system cells (106-108).

Another important factor associated with HLA is the aberrant expression of HLA-G, as most tumors neo-express HLA-G at various stages of their evolution and HLA-G neo-expression deactivates all antitumor immune responses. As plasmatic (free or vesicular) and membrane-bound (m) HLA-G expression is significantly increased in most cancer types and associated with poor prognosis, it is possible to use the levels of membrane-bound human leukocyte antigen- $G$ on tumor and immune cells and/or sHLA-G (free or as part of extracellular vesicles) in plasma as diagnostic and prognostic tools in cancer patients. Furthermore, HLA-G may also serve as a therapeutic target for blocking $\mathrm{mAbs}$ or interfering RNAs (109).

HLA-G expression, in contrast with CTLA-4 and PD1, does not depend on T-cell activation and is capable of blocking antitumor immune responses by inhibiting all immune effectors, from APC activation to effector priming, as well as blocking activated CTL and NK cell function. Taking into account all the scientific evidence concerning the function of HLA loss of expression, it is possible to speculate that a cancer therapy targeting aberrant HLA-I expression would restore T-cell recognition of tumor cells and thus improve the clinical response to immunotherapies based on CTLA-4, PD1 and PDL1 expression. In addition, silencing of HLA-G expression or blocking the inhibitory ILT-2/4 receptors on immune cells may prevent inhibitory signaling and restore the antitumor effector capacity of immune cells. It may be possible to extend HLA-based clinical applications to the design of promising tools not only for diagnostic application to improve immunotherapeutic management of the disease, but also as prognostic markers for the clinical outcome of therapies, including NACT. A variety of studies focused on targeted therapies to modify the immunoregulatory nature of the tumor microenvironment are underway, and perhaps in the future, early diagnosis will allow early immunotherapeutic treatment, thus leading to improved survival rates.

\section{Acknowledgements}

The author sincerely thanks Dr Laura Sanchez, Dr Silvia Serrano, Dr Alba Lucia Combita and Dr Nataly Cruz from the Cancer Biology Research Group at the National Cancer Institute of Colombia in Bogotá, Colombia, for their careful review of the manuscript. The present study received financial support through an INC/DNP grant (grant no. 41030610-109).

\section{References}

1. Hanahan D and Weinberg RA: Hallmarks of cancer: The next generation. Cell 144: 646-674, 2011.

2. Grivennikov SI, Greten FR and Karin M: Immunity, Inflammation and cancer. Cell 140: 883-899, 2010

3. Van den Boorn JG and Hartmann G: Turning tumors into vaccines: Co-opting the innate immune system. Immunity 39: 27-37, 2013

4. Campoli $\mathrm{M}$ and Ferrone S: HLA antigen changes in malignant cells: Epigenetic mechanisms and biologic significance. Oncogene 27: 5869-5885, 2008.

5. Chang CC, Campoli M and Ferrone S: Classical and nonclassical HLA class I antigen and NK Cell-activating ligand changes in malignant cells: Current challenges and future directions. Adv Cancer Res 93: 189-234, 2005.

6. Garrido F, Cabrera T, Concha A, Glew S, Ruiz-Cabello F and Stern PL: Natural history of HLA expression during tumour development. Immunol Today 14: 491-499, 1993.

7. Garrido F, Ruiz-Cabello F, Cabrera T, Pérez-Villar JJ, López-Botet M, Duggan-Keen M and Stern PL: Implications for immunosurveillance of altered HLA class I phenotypes in human tumours. Immunol Today 18: 89-95 1997.

8. Koopman LA, Corver WE, van der Slik AR, Giphart MJ and Fleuren GJ: Multiple genetic alterations cause frequent and heterogeneous human histocompatibility leukocyte antigen class I loss in cervical cancer. J Exp Med 191: 961-976, 2000.

9. Moreau P, Rousseau P, Rouas-Freiss N, Le Discorde M, Dausset J and Carosella ED: HLA-G protein processing and transport to the cell surface. Cell Mol Life Sci 59: 1460-1466, 2002.

10. Adams JL, Smothers J, Srinivasan R and Hoos A: Big opportunities for small molecules in immuno-oncology. Nat Rev Drug Discov 14: 603-622, 2015.

11. Srinivasan R and Wolchok JD: Tumor antigens for cancer immunotherapy: Therapeutic potential of xenogeneic DNA vaccines. J Transl Med 2: 12, 2004.

12. Waldhauer I and Steinle A: NK cells and cancer immunosurveillance. Oncogene 27: 5932-5943, 2008.

13. Jaeger BN and Vivier E: Natural killer cell tolerance: Control by self or self-control? Cold Spring Harb Perspect Biol 4: pii: a007229, 2012.

14. Pegram HJ, Andrews DM, Smyth MJ, Darcy PK and Kershaw MH: Activating and inhibitory receptors of natural killer cells. Immunol Cell Biol 89: 216-224, 2011.

15. Yokoyama WM and Kim S: Licensing of natural killer cells by self-major histocompatibility complex class I. Immunol Rev 214: 143-154, 2006.

16. Clynes RA, Towers TL, Presta LG and Ravetch JV: Inhibitory Fc receptors modulate in vivo cytotoxicity against tumor targets. Nat Med 6: 443-496, 2000.

17. Hayakawa $\mathrm{Y}$ and Smyth MJ: Innate immune recognition and suppression of tumors. Adv Cancer Res 95: 293-322, 2006.

18. Lennerz V, Fatho M, Gentilini C, Frye RA, Lifke A, Ferel D, Wölfel C, Huber C and Wölfel T: The response of autologous T cells to a human melanoma is dominated by mutated neoantigens. Proc Natl Acad Sci USA 102: 16013-16018, 2005.

19. Perez-Diez A, Joncker NT, Choi K, Chan WF, Anderson CC, Lantz $\mathrm{O}$ and Matzinger P: CD4 cells can be more efficient at tumor rejection than CD8 cells. Blood 109: 5346-5354, 2007.

20. Gotter J, Brors B, Hergenhahn M and Kyewski B: Medullary epithelial cells of the human thymus express a highly diverse selection of tissue-specific genes colocalized in chromosomal clusters. J Exp Med 199: 155-166, 2004. 
21. Gerloni $\mathrm{M}$ and Zanetti M: CD4 T cells in tumor immunity. Springer Semin Immunopathol 27: 37-48, 2005.

22. Palm NW and Medzhitov R: Pattern recognition receptors and control of adaptive immunity. Immunol Rev 227: 221-233, 2009.

23. Smith-Garvin JE, Koretzky GA and Jordan MS: T cell activation. Annu Rev Immunol 27: 591-619, 2009.

24. Pardoll DM: The blockade of immune checkpoints in cancer immunotherapy. Nat Rev Cancer 12: 252-264, 2012.

25. Pico de Coaña Y, Choudhury A and Kiessling R: Checkpoint blockade for cancer therapy: Revitalizing a suppressed immune system. Trends Mol Med 21: 482-491, 2015.

26. Carreno BM and Collins M: The B7 family of ligands and its receptors: New pathways for costimulation and inhibition of immune responses. Annu Rev Immunol 20: 29-53, 2002.

27. Nishimura H, Okazaki T, Tanaka Y, Nakatani K, Hara M, Matsumori A, Sasayama S, Mizoguchi A, Hiai H, Minato N and Honjo T: Autoimmune dilated cardiomyopathy in PD-1 receptor-deficient mice. Science 291: 319-322, 2001.

28. Waterhouse P, Penninger JM, Timms E, Wakeham A Shahinian A, Lee KP, Thompson CB, Griesser H and Mak TW: Lymphoproliferative disorders with early lethality in mice deficient in Ctla-4. Science 270: 985-988, 1995.

29. Chemnitz JM, Parry RV, Nichols KE, June CH and Riley JL: SHP-1 and SHP-2 associate with immunoreceptor tyrosine-based switch motif of programmed death 1 upon primary human $\mathrm{T}$ cell stimulation, but only receptor ligation prevents $\mathrm{T}$ cell activation. J Immunol 173: 945-954, 2004.

30. Kirchhof MG, Chau LA, Lemke CD, Vardhana S, Darlington PJ, Márquez ME, Taylor R, Rizkalla K, Blanca I, Dustin ML and Madrenas J: Modulation of T cell activation by stomatin-like protein 2. J Immunol 181: 1927-1936, 2008.

31. Teft WA, Kirchhof MG and Madrenas J. A molecular perspective of CTLA-4 function. Annu Rev Immunol 24: 65-97, 2006.

32. Contini P, Ghio M, Poggi A, Filaci G, Indiveri F, Ferrone S and Puppo F: Soluble HLA-A,-B,-C and -G molecules induce apoptosis in T and NK CD8+ cells and inhibit cytotoxic T cell activity through CD8 ligation. Eur J Immunol 33: 125-134, 2003.

33. Le Bouteiller P, Fons P, Herault JP, Bono F, Chabot S, Cartwright JE and Bensussan A: Soluble HLA-G and control of angiogenesis. J Reprod Immunol 76: 17-22, 2007.

34. Colonna M, Samaridis J, Cella M, Angman L, Allen RL, O'Callaghan CA, Dunbar R, Ogg GS, Cerundolo V and Rolink A: Human myelomonocytic cells express an inhibitory receptor for classical and nonclassical MHC class I molecules. J Immunol 160: 3096-3100, 1998.

35. Rajagopalan S and Long EO: A human histocompatibility leukocyte antigen (HLA)-G-specific receptor expressed on all natura killer cells. J Exp Med 189: 1093-1100, 1999.

36. Pankratz S, Ruck T, Meuth SG and Wiendl H: CD4(+)HLA-G(+) regulatory T cells: Molecular signature and pathophysiological relevance. Hum Immunol 77: 727-733, 2016.

37. Kim R, Emi M and Tanabe K: Cancer immunoediting from immune surveillance to immune escape. Immunology 121: 1-14, 2007.

38. Vesely MD, Kershaw MH, Schreiber RD and Smyth MJ: Natural innate and adaptive immunity to cancer. Annu Rev Immunol 29: 235-271, 2011

39. Monjazeb AM, Zamora AE, Grossenbacher SK, Mirsoian A, Sckisel GD and Murphy WJ: Immunoediting and antigen loss: Overcoming the achilles heel of immunotherapy with antigen non-specific therapies. Front Oncol 3: 197, 2013.

40. Khong HT and Restifo NP: Natural selection of tumor variants in the generation of 'tumor escape' phenotypes. Nat Immunol 3 . 999-1005, 2002

41. Koebel CM, Vermi W, Swann JB, Zerafa N, Rodig SJ, Old LJ, Smyth MJ and Schreiber RD: Adaptive immunity maintains occult cancer in an equilibrium state. Nature 450: 903-907, 2007.

42. Gunderson AJ and Coussens LM: B cells and their mediators as targets for therapy in solid tumors. Exp Cell Res 319: 1644-1649, 2013.

43. Esquivel-Velázquez M, Ostoa-Saloma P, Palacios-Arreola MI, Nava-Castro KE, Castro JI and Morales-Montor J: The role of cytokines in breast cancer development and progression. J Interferon Cytokine Res 35: 1-16, 2015.

44. Lippitz BE: Cytokine patterns in patients with cancer: A systematic review. Lancet Oncol 14: e218-e228, 2013

45. Gajewski TF, Meng Y, Blank C, Brown I, Kacha A, Kline J and Harlin H: Immune resistance orchestrated by the tumor microenvironment. Immunol Rev 213: 131-145, 2006.
46. Gajewski TF, Fuertes M, Spaapen R, Zheng Y and Kline J: Molecular profiling to identify relevant immune resistance mechanisms in the tumor microenvironment. Curr Opin Immunol 23. 286-292, 2011

47. Mahoney KM and Atkins MB: Prognostic and predictive markers for the new immunotherapies. Oncology (Williston Park) 28 (Suppl 3): S39-S48, 2014.

48. Wong SC, Puaux AL, Chittezhath M, Shalova I, Kajiji TS, Wang X, Abastado JP, Lam KP and Biswas SK: Macrophage polarization to a unique phenotype driven by B cells. Eur J Immunol 40: 2296-2307, 2010.

49. Loi S, Sirtaine N, Piette F, Salgado R, Viale G, Van Eenoo F, Rouas G, Francis P, Crown JP, Hitre E, et al: Prognostic and predictive value of tumor-infiltrating lymphocytes in a phase III randomized adjuvant breast cancer trial in node-positive breast cancer comparing the addition of docetaxel to doxorubicin with doxorubicin-based chemotherapy: BIG 02-98. J Clin Oncol 31: 860-867, 2013

50. Tanchot C, Terme M, Pere H, Tran T, Benhamouda N, Strioga M, Banissi C, Galluzzi L, Kroemer G and Tartour E: Tumor-infiltrating regulatory T cells: Phenotype, role, mechanism of expansion in situ and clinical significance. Cancer Microenviron 6: 147-157, 2013.

51. Petersson M, Charo J, Salazar-Onfray F, Noffz G, Mohaupt M, Qin Z, Klein G, Blankenstein T and Kiessling R: Constitutive IL-10 production accounts for the high NK sensitivity, low MHC class I expression, and poor transporter associated with antigen processing (TAP)-1/2 function in the prototype NK target YAC-1. J Immunol 161: 2099-2105, 1998.

52. Salazar-Onfray F, Charo J, Petersson M, Freland S, Noffz G, Qin Z, Blankenstein T, Ljunggren $\mathrm{HG}$ and Kiessling R: Down-regulation of the expression and function of the transporter associated with antigen processing in murine tumor cell lines expressing IL-10. J Immunol 159: 3195-3202, 1997.

53. Chen CJ, Sung WW, Su TC, Chen MK, Wu PR, Yeh KT, Ko JL and Lee $\mathrm{H}$ : High expression of interleukin 10 might predict poor prognosis in early stage oral squamous cell carcinoma patients. Clin Chim Acta 415: 25-30, 2013.

54. Goncalves AS, Wastowski IJ, Capeletti LR, Sacono NT, Cortez AP, Valadares MC, Silva TA and Batista AC: The clinicopathologic significance of the expression of HLA-G in oral squamous cell carcinoma. Oral Surg Oral Med Oral Pathol Oral Radiol 117: 361-368, 2014.

55. Levy EM, Bianchini M, Von Euw EM, Barrio MM, Bravo AI, Furman D, Domenichini E, Macagno C,Pinsky V,Zucchini C, et al: Human leukocyte antigen-E protein is overexpressed in primary human colorectal cancer. Int J Oncol 32: 633-641, 2008.

56. Gasparoto TH, de Souza Malaspina TS, Damante JH, de Mello EF Jr, Ikoma MR, Garlet GP, Costa MR, Cavassani KA, da Silva JS and Campanelli AP: Regulatory T cells in the actinic cheilitis. J Oral Pathol Med 43: 754-760, 2014.

57. Mendez R, Aptsiauri N, Del Campo A, Maleno I, Cabrera T, Ruiz-Cabello F, Garrido F and Garcia-Lora A: HLA and melanoma: Multiple alterations in HLA class I and II expression in human melanoma cell lines from ESTDAB cell bank. Cancer Immunol Immunother 58: 1507-1515, 2009.

58. Ferns DM, Heeren AM, Samuels S, Bleeker MC, de Gruijl TD, Kenter GG and Jordanova ES: Classical and non-classical HLA class I aberrations in primary cervical squamous- and adenocarcinomas and paired lymph node metastases. J Immunother Cancer 4: 78, 2016

59. Campoli M and Ferrone S: HLA antigen and NK cell activating ligand expression in malignant cells: A story of loss or acquisition. Semin Immunopathol 33: 321-334, 2011.

60. Lynge Nilsson L, Djurisic S and Hviid TV: Controlling the immunological crosstalk during conception and pregnancy: HLA-G in reproduction. Front Immunol 5: 198, 2014.

61. Cabrera T, López-Nevot MA, Gaforio JJ, Ruiz-Cabello F and Garrido F: Analysis of HLA expression in human tumor tissues. Cancer Immunol Immunother 52: 1-9, 2003.

62. Goncalves AS, Oliveira JP, Oliveira CF, Silva TA, Mendonca EF, Wastowski IJ and Batista AC: Relevance of HLA-G, HLA-E and IL-10 expression in lip carcinogenesis. Hum Immunol 77: 785-790, 2016

63. Reimers MS, Engels CC, Putter H, Morreau H, Liefers GJ, van de Velde CJ and Kuppen PJ: Prognostic value of HLA class I, HLA-E, HLA-G and Tregs in rectal cancer: A retrospective cohort study. BMC Cancer 14: 486, 2014.

64. Rouas-Freiss N, Moreau P, Ferrone S and Carosella ED: HLA-G proteins in cancer: Do they provide tumor cells with an escape mechanism? Cancer Res 65: 10139-10144, 2005. 
65. Carosella ED, Moreau P, Le Maoult J, Le Discorde M, Dausset J and Rouas-Freiss N: HLA-G molecules: From maternal-fetal tolerance to tissue acceptance. Adv Immunol 81: 199-252, 2003.

66. LeMaoult J, Zafaranloo K, Le Danff C and Carosella ED HLA-G up-regulates ILT2, ILT3, ILT4, and KIR2DL4 in antigen presenting cells, NK cells, and T cells. FASEB J 19: 662-664, 2005.

67. Braud VM, Allan DS, O'Callaghan CA, Söderström K, D'Andrea A, Ogg GS, Lazetic S, Young NT, Bell JI, Phillips JH, et al: HLA-E binds to natural killer cell receptors CD94/NKG2A, B and C. Nature 391: 795-799, 1998.

68. Braud VM, Aldemir H, Breart B and Ferlin WG: Expression of CD94-NKG2A inhibitory receptor is restricted to a subset of CD8+ T cells. Trends Immunol 24: 162-164, 2003.

69. Garrido F, Cabrera T and Aptsiauri N: "Hard" and "soft" lesions underlying the HLA class I alterations in cancer cells: Implications for immunotherapy. Int J Cancer 127: 249-256, 2010.

70. Vermeulen CF, Jordanova ES, Zomerdijk-Nooijen YA, ter Haar NT, Peters AA and Fleuren GJ: Frequent HLA class I loss is an early event in cervical carcinogenesis. Hum Immunol 66 : 1167-1173, 2005.

71. Brady CS, Bartholomew JS, Burt DJ, Duggan-Keen MF, Glenville S, Telford N, Little AM, Davidson JA, Jimenez P, Ruiz-Cabello F, et al: Multiple mechanisms underlie HLA dysregulation in cervical cancer. Tissue Antigens 55: 401-411, 2000.

72. Maleno I, Aptsiauri N, Cabrera T, Gallego A, Paschen A, López-Nevot MA and Garrido F: Frequent loss of heterozygosity in the $\beta 2$-microglobulin region of chromosome 15 in primary human tumors. Immunogenetics 63: 65-71, 2011.

73. Rodriguez JA, Galeano L, Palacios DM, Gómez C, Serrano ML, Bravo MM and Combita AL: Altered HLA class I and HLA-G expression is associated with IL-10 expression in patients with cervical cancer. Pathobiology 79: 72-83, 2012.

74. Carosella ED, Rouas-Freiss N, Tronik-Le Roux D, Moreau P and LeMaoult J: HLA-G: An immune checkpoint molecule. Adv Immunol 127: 33-144, 2015.

75. Seliger B, Ritz U and Ferrone S: Molecular mechanisms of HLA class I antigen abnormalities following viral infection and transformation. Int J Cancer 118: 129-138, 2006.

76. Ristich V, Liang S, Zhang W, Wu J and Horuzsko A: Tolerization of dendritic cells by HLA-G. Eur J Immunol 35: 1133-1142, 2005.

77. Caumartin J, Favier B, Daouya M, Guillard C, Moreau P, Carosella ED and LeMaoult J: Trogocytosis-based generation of suppressive NK cells. EMBO J 26: 1423-1433, 2007.

78. König L, Kasimir-Bauer S, Hoffmann O, Bittner AK, Wagner B, Manvailer LF, Schramm S, Bankfalvi A, Giebel B, Kimmig R, et al: The prognostic impact of soluble and vesicular HLA-G and its relationship to circulating tumor cells in neoadjuvant treated breast cancer patients. Hum Immunol 77: 791-799, 2016.

79. Bainbridge DR, Ellis SA and Sargent IL: The short forms of HLA-G are unlikely to play a role in pregnancy because they are not expressed at the cell surface. J Reprod Immunol 47: 1-16, 2000.

80. Gong FL, Feng XW and Grosse-Wilde H: Impaired antigen-presenting capability of monocytes correlated with their decreased expression of HLA-II antigens in patients with myeloid leukemia. J Tongji Med Univ 13: 65-70, 1993.

81. Yang XX, Pan HZ, Li PY, Li FX, Xu WW, Wu YS, Yao GY and Li M: HLA class II variants in Chinese breast cancer patients. Asian Pac J Cancer Prev 12: 3075-3079, 2011.

82. Hu JM, Li L, Chen YZ, Liu C, Cui X, Yin L, Yang L, Zou H, Pang L, Zhao J, et al: HLA-DRB1 and HLA-DQB1 methylation changes promote the occurrence and progression of Kazakh ESCC. Epigenetics 9: 1366-1373, 2014

83. Liang J, Xu A, Xie Y, Awonuga AO and Lin Z: Some but not all of HLA-II alleles are associated with cervical cancer in Chinese women. Cancer Genet Cytogenet 187: 95-100, 2008

84. National Cancer Institute. Chemotherapy and you U.S. Department of health and human services national institutes of health, 2011

85. Taylor A and Powell ME: Intensity-modulated radiotherapy-what is it? Cancer Imaging 4: 68-73, 2004.

86. Galluzzi L, Vacchelli E, Bravo-San Pedro JM, Buqué A, Senovilla L, Baracco EE, Bloy N, Castoldi F, Abastado JP, Agostinis P, et al: Classification of current anticancer immunotherapies. Oncotarget 5: 12472-12508, 2014.

87. Copier J, Dalgleish AG, Britten CM, Finke LH, Gaudernack G, Gnjatic S, Kallen K, Kiessling R, Schuessler-Lenz M, Singh $\mathrm{H}$, et al: Improving the efficacy of cancer immunotherapy. Eur J Cancer 45: 1424-1431, 2009.
88. Young PA, Morrison SL and Timmerman JM: Antibody-cytokine fusion proteins for treatment of cancer: Engineering cytokines for improved efficacy and safety. Semin Oncol 41: 623-636, 2014.

89. Robert C, Thomas L, Bondarenko I, O'Day S, Weber J, Garbe C, Lebbe C, Baurain JF, Testori A, Grob JJ, et al: Ipilimumab plus dacarbazine for previously untreated metastatic melanoma. N Engl J Med 364: 2517-2526, 2011.

90. Attia P, Phan GQ, Maker AV, Robinson MR, Quezado MM, Yang JC, Sherry RM, Topalian SL, Kammula US, Royal RE, et al: Autoimmunity correlates with tumor regression in patients with metastatic melanoma treated with anti-cytotoxic T-lymphocyte antigen-4. J Clin Oncol 23: 6043-6053, 2005.

91. Fong L and Small EJ: Anti-cytotoxic T-lymphocyte antigen-4 antibody: The first in an emerging class of immunomodulatory antibodies for cancer treatment. J Clin Oncol 26: 5275-5283, 2008.

92. Aerts M, Benteyn D, Van Vlierberghe H, Thielemans K and Reynaert H: Current status and perspectives of immune-based therapies for hepatocellular carcinoma. World J Gastroenterol 22: 253-261, 2016.

93. Boasberg P, Hamid O and O'Day S: Ipilimumab: Unleashing the power of the immune system through CTLA-4 blockade. Semin Oncol 37: 440-449, 2010

94. Ugurel S, Röhmel J, Ascierto PA, Flaherty KT, Grob JJ, Hauschild A, Larkin J, Long GV, Lorigan P, McArthur GA, et al: Survival of patients with advanced metastatic melanoma: The impact of novel therapies. Eur J Cancer 53: 125-134, 2015.

95. Thor Straten $\mathrm{P}$ and Garrido F: Targetless T cells in cancer immunotherapy. J Immunother Cancer 4: 23, 2016.

96. Vavrova K, Vrabcova P, Filipp D, Bartunkova J and Horvath R: Generation of T cell effectors using tumor cell-loaded dendritic cells for adoptive T cell therapy. Med Oncol 33: 136, 2016.

97. Fesnak AD, June CH and Levine BL: Engineered T cells: The promise and challenges of cancer immunotherapy. Nat Rev Cancer 16: 566-581, 2016.

98. Redeker A and Arens R: Improving adoptive T cell therapy: The particular role of $t$ cell costimulation, cytokines, and post-transfer vaccination. Front Immunol 7: 345, 2016.

99. Del Campo AB, Aptsiauri N, Méndez R, Zinchenko S, Vales A, Paschen A, Ward S, Ruiz-Cabello F, González-Aseguinolaza G and Garrido F: Efficient recovery of HLA class I expression in human tumor cells after beta2-microglobulin gene transfer using adenoviral vector: Implications for cancer immunotherapy. Scand J Immunol 70: 125-135, 2009.

100. Del Campo AB, Carretero J, Muñoz JA, Zinchenko S, Ruiz-Cabello F, González-Aseguinolaza G, Garrido F and Aptsiauri N: Adenovirus expressing $\beta 2$-microglobulin recovers HLA class I expression and antitumor immunity by increasing T-cell recognition. Cancer Gene Ther 21: 317-332, 2014.

101. Penaloza-MacMaster P, Kamphorst AO, Wieland A, Araki K, Iyer SS, West EE, O’Mara L, Yang S, Konieczny BT, Sharpe AH, et al: Interplay between regulatory T cells and PD-1 in modulating $\mathrm{T}$ cell exhaustion and viral control during chronic LCMV infection. J Exp Med 211: 1905-1918, 2014.

102. Wherry EJ: T cell exhaustion. Nat Immunol 12: 492-499, 2011.

103. Pauken KE and Wherry EJ: Overcoming T cell exhaustion in infection and cancer. Trends Immunol 36: 265-276, 2015.

104. Page DB, Postow MA, Callahan MK, Allison JP and Wolchok JD: Immune modulation in cancer with antibodies. Annu Rev Med 65: 185-202, 2014

105. Mellman I, Coukos G and Dranoff G: Cancer immunotherapy comes of age. Nature 480: 480-489, 2011.

106. Okamoto M, Kobayashi M, Yonemitsu Y, Koido S and Homma S: Dendritic cell-based vaccine for pancreatic cancer in Japan. World J Gastrointest Pharmacol Ther 7: 133-138, 2016.

107. Wang Z, Liu Y, Zhang Y, Shang Y and Gao Q: MDSC-decreasing chemotherapy increases the efficacy of cytokine-induced killer cell immunotherapy in metastatic renal cell carcinoma and pancreatic cancer. Oncotarget 7: 4760-4769, 2016

108. Zhao X, Ji CY, Liu GQ, Ma DX, Ding HF, Xu M and Xing J: Immunomodulatory effect of DC/CIK combined with chemotherapy in multiple myeloma and the clinical efficacy. Int $\mathrm{J}$ Clin Exp Pathol 8: 13146-13155, 2015.

109. Amiot L, Ferrone S, Grosse-Wilde H and Seliger B: Biology of HLA-G in cancer: A candidate molecule for therapeutic intervention? Cell Mol Life Sci 68: 417-431, 2011. 